\title{
Synthesis and Antibacterial Activity of Cobalt(II) Complex of Curcumin
}

\author{
K. GIRISH, B. C. CHANNU ${ }^{1}$ AND A. R. BABA ${ }^{1 *}$ \\ Postgraduate Department of Microbiology, ${ }^{1}$ Postgraduate Department of Chemistry, Maharani's Science College for Women, \\ Mysuru-570 005, India
}

\author{
Girish et al.: Antibacterial Activity of Curcumin-cobalt(II) Complex
}

\begin{abstract}
To improve the bioavailability of curcumin numerous approaches were attempted, which included complexation with metal ions. In the present study, a metal ion complex of cobalt(II) with curcumin was synthesized and screened for in vitro antibacterial activity in comparison with curcumin on seven bacterial strains, Bacillus subtilis, Escherichia coli, Klebsiella pneumoniae, Salmonella typhi, Shigella flexneri, Proteus vulgaris and Staphylococcus aureus. The cobalt-curcumin complex was effective against all strains tested and the activity was greater than that exhibited by curcumin. Comparison of the inhibitory activity with the macrolide antibiotic azithromycin revealed that cobalt-curcumin complex was as active as the antibiotic. The cobalt-curcumin complex could be a suitable candidate for further in vivo investigations. This is the first report of antibacterial activity of cobalt-curcumin complex against all the bacterial strains tested except Escherichia coli.
\end{abstract}

Key words: Curcumin, cobalt-curcumin complex, antibacterial activity

The plant kingdom is a rich store house of constituents that have nutritional as well as medicinal value. Development of resistance to the currently used antimicrobials and harmful side effects of existing drugs along with the increasing popularity of traditional medicine has led researchers to investigate the antimicrobial compounds in plants ${ }^{[1]}$. Medicinal plants are an important source to find new antiinfective agents $^{[2]}$. Curcuma longa (turmeric) is one such medicinal plant related to Zingberiaceae family with a long history of medicinal use in South Asia, being used in the Ayurveda, the traditional Indian medicine system $^{[3]}$. Turmeric is an ancient spice and a traditional remedy that has been used as a medicine, condiment and a flavoring agent. Turmeric powder, derived from the rhizome of $C$. longa, is commonly used as a spice, food preservative, and food-coloring agent. Among the constituents, curcumin (1E,6E)-1,7-bis (4-hydroxy-3-methoxyphenyl)-1,6-heptadiene-3,5dione; diferuloylmethane), a yellow bioactive pigment, is the major component of turmeric ${ }^{[4]}$. It is amongst the more successful chemopreventive compounds investigated in recent years and has shown to exhibit antioxidant, antiinflammatory, antiviral, antibacterial, antifungal, and anticancer activities. It thus, possesses potential activity against various malignant diseases, diabetes, allergies, arthritis, Alzheimer's disease, and

*Address for correspondence E-mail: arbaba71@rediffmail.com

January-February 2019 other chronic illnesses ${ }^{[5]}$. Several studies have reported the broad-spectrum antimicrobial activity of curcumin including antibacterial, antiviral, and antifungal activities. Curcumin exhibited significant antibacterial activity with minimum inhibitory concentration (MIC) values between 5 and $50 \mu \mathrm{g} / \mathrm{ml}$ against 65 clinical isolates of Helicobacter pylori ${ }^{[6]}$. Curcumin showed inhibitory activity against methicillin-resistant Staphylococcus aureus strains with MIC value of $125-250 \mu \mathrm{g} / \mathrm{ml}^{[7]}$. Curcumin was also effective against Enterococcus faecalis, Escherichia coli and Pseudomonas aeruginosa. The bactericidal activity of curcumin was found to be due to damaging the bacterial membrane ${ }^{[8]}$. Curcumin showed antiviral activity against influenza viruses PR8, H1N1 and H6N1. More than $90 \%$ reduction in virus load in cell culture was observed in the presence of $30 \mu \mathrm{M}$ curcumin ${ }^{[9]}$. Curcumin was found to be an inhibitor of HIV-1 and HIV-2 protease with an $\mathrm{IC}_{50}$ of 100 and $250 \mu \mathrm{M}$, respectively ${ }^{[10]}$. Curcumin exhibited antiviral activity against coxsackievirus by reducing viral RNA expression, protein synthesis,

This is an open access article distributed under the terms of the Creative Commons Attribution-NonCommercial-ShareAlike 3.0 License, which allows others to remix, tweak, and build upon the work non-commercially, as long as the author is credited and the new creations are licensed under the identical terms

Accepted 18 November 2018

Revised 17 April 2018

Received 13 April 2017

Indian J Pharm Sci 2019;81(1):150-155 
and virus titer $^{[11]}$. Curcumin is fungicidal against Candida species with MIC values ranging from 250 to $2000 \mu \mathrm{g} / \mathrm{ml}^{[12]}$. Curcumin exerted antifungal effect against two phytophagous fungi, Fusarium solani and Helminthosporium oryzae $e^{[13]}$. Curcumin exerted greater effect against Paracoccidioides brasiliensis than that of fluconazole ${ }^{[14]}$. However, low solubility, poor absorption and fast metabolism leads to low bioavailability and lack of target delivery limits the usage of curcumin as a therapeutic agent ${ }^{[3]}$.

The above limitations can be overcome by attaching curcumin to ligands that enhance its solubility, bioavailability and slow down the metabolism ${ }^{[3]}$. Complexation of curcumin with transition metals has attracted much interest over the past years as one of the useful requirement for increasing bioavailability of curcumin. Several metallocomplexes of curcumin have been synthesized characterized and evaluated for various biological activities. Complexes of boron, copper, iron, manganese, palladium, vanadyl, gallium, and indium have been reported ${ }^{[15-21]}$. Some metals are known for their antibacterial activity and in some cases as effective therapeutic agents against bacterial diseases $^{[22]}$. Cobalt is one of the important trace elements, which is regarded as an essential element for humans and is less toxic than non-essential metals ${ }^{[23]}$. However, no study reported attempts to form cobalt complexes with curcumin. Owing to this, in the present study curcumin was complexed with cobalt and screened for antibacterial activity. Many reports on the antibacterial properties of cobalt complexes have appeared in the literature, wherein $\mathrm{Co}$ (II) complexes were the most studied, presumably due to their aqueous stability, availability and ease of synthesis ${ }^{[24]}$. Cobaltamino acid complexes were found to be antibacterial against $E$. coli, Bacillus subtilis and Micrococcus luteus. $M$. luteus was the most susceptible strain tested ${ }^{[25]}$. Cobalt complex with histidine showed significant antibacterial and antifungal activity against multidrug resistant pathogens such as $P$. aeruginosa, Vibrio cholerae, Salmonella typhi, E. coli, Klebsiella pneumoniae, S. aureus, Aspergillus niger, A. flavus and C. albicans in comparison to commercial antibiotics ${ }^{[26]}$. Thiamine-cobalt complex was active against Gramnegative bacteria, S. paratyphi B and Vibrio species ${ }^{[27]}$. Cobalt is generally not considered to be a very toxic element. Vitamin B12 is a cobaloxime, a naturally occurring cobalt complex containing a glyoxime ligand ${ }^{[24]}$. Toxicity of cobalt is reduced in the form of a complex. The toxicity of cobalt complex was determined using the brine shrimp lethality test. The $\mathrm{LC}_{50}$ value of $362.24 \mathrm{mg} / \mathrm{l}$ indicated that the complex was not toxic ${ }^{[28]}$. However, toxicity is concentrationdependent and exposure to higher concentrations might adversely affect the human health ${ }^{[24]}$.

Raw turmeric was finely powdered and about $50 \mathrm{~g}$ of turmeric powder was refluxed with ethanol for $5 \mathrm{~h}$. After refluxing, the mixture was filtered, filtrate was collected and residue discarded. Filtrate was distilled off and the residue remained in the round bottom flask was washed with petroleum ether $\left(60-80^{\circ}\right)$ to get a residue of curcuminoids, which was further purified ${ }^{[29]}$.

The crude extract was subjected to column chromatography on a silica gel glass column. About $2 \mathrm{~g}$ of crude curcuminoids were mixed with $1 \mathrm{ml}$ methanol and loaded on to the column $(30 \times 1.5 \mathrm{~cm})$ and eluted with chloroform:methanol (90:10). All the collected fractions were subjected to thin-layer chromatography and yellow spots were detected. Finally curcumin was recrystallized from hot ethanol, to get orange-red crystalline compound, which was stored in a darkcolored container.

Curcumin $(0.92 \mathrm{~g}, 0.1 \mathrm{M})$ solution in $25 \mathrm{ml}$ methanol was prepared and heated gently at $40-50^{\circ}$ for $15 \mathrm{~min}$. A solution of cobalt(II) sulphate $\left(\mathrm{CoSO}_{4}\right)$ was prepared $(0.353 \mathrm{~g}, 0.05 \mathrm{M})$ in $25 \mathrm{ml}$ of methanol and added to curcumin solution, stirred continuously. $\mathrm{pH}$ of the reaction mixture was maintained at $7.5-9.5$ by adding $5 \%$ ammonia solution. Heating was continued on a water bath at $50-60^{\circ}$ with continuous stirring. Dark brownish-colored complex that precipitated was filtered in a Buchner funnel with suction and the compound was washed with deionized water and rinsed with methanol till unreacted reagent and curcumin was removed from the complex.

Fourier-transform infrared (FTIR) spectra of curcumin and Co(II)-curcumin complex were recorded on a FTIR (Shimadzu 2200) equipped with a deuterated triglycine sulfate detector with a resolution fixed to $4 \mathrm{~cm}^{-1}$. The pellets of sample (10 $\mathrm{mg})$ and potassium bromide (200 $\mathrm{mg}$ ) were prepared by compressing the powder at 5 bars for 5 min on a $\mathrm{KBr}$ press and the spectrum was scanned in the wave number range of $3600-4000 \mathrm{~cm}^{-1}$.

Differential scanning calorimetric (DSC) thermograms were obtained on a Universal V4.5A TA Instruments, using 1.0 to $1.5 \mathrm{mg}$ samples packed in an aluminium crucible. Samples were heated at $10 \% \mathrm{~min}$ from room 
temperature to $400^{\circ}$, in a dynamic nitrogen atmosphere (flow rate $=200 \mathrm{ml} / \mathrm{min}$ ).

Seven bacteria, B. subtilis, E. coli, K. pneumonia, S. typhi, S. flexneri, P. vulgaris and S. aureus served as test pathogens for the antibacterial assay. The organisms used in this experiment were maintained as pure cultures on nutrient agar slants and stored in refrigerator until used. All these cultures were inoculated aseptically on to fresh and sterile nutrient agar medium slants, incubated for $24 \mathrm{~h}$ and used. Stock solutions of curcumin and its Co(II) complex $(10 \mathrm{mg} / 1.0 \mathrm{ml}=10000 \mathrm{ppm})$ were prepared by dissolving in dimethyl sulphoxide (DMSO). Using this stock solution all the concentrations tried, 1000 ppm $(1 \mathrm{mg} / \mathrm{ml})$ to $6000 \mathrm{ppm}(6 \mathrm{mg} / \mathrm{ml})$, were prepared by diluting with distilled water. Stock solutions of curcumin and cobalt(II)-curcumin complex (Co(II)complex) were made in DMSO to ensure complete solubilisation and then diluted in aqueous broth to obtain different concentrations ${ }^{[4,17,30]}$.

Antibacterial activity assay was carried out using the cup diffusion method on nutrient agar medium. Bacterial cultures were inoculated to peptone water in different test tubes and incubated at $37^{\circ}$ in incubator for $20 \mathrm{~min}$. Sterile nutrient agar plates were prepared having $20 \mathrm{ml}$ of medium in a $9 \mathrm{~cm}$ plate. A lawn of inoculum was made from the incubated cultures using sterilized cotton swabs and allowed as such for few minutes. Wells were made equidistantly on the medium using a 5-mm cork borer. Hundred microliters of different concentrations of curcumin and its $\mathrm{Co}$ (II) complex were added to different wells and $100 \mu 1$ of DMSO was used as the control, which was added to a well made at the centre of the plate. All test plates were incubated at $37^{\circ}$ for $24 \mathrm{~h}$. The least concentration of each extract showing a clear zone of inhibition was taken as the MIC. Experiment was also carried out with azithromycin $(15 \mu \mathrm{g} /$ disc $)$ that served as a reference.

Curcumin content in turmeric is very less, which is only about 1-3\%. Local variety of turmeric available in the market was used in the current experiment, which yielded $1-1.5 \mathrm{~g} / 100 \mathrm{~g}$ of turmeric powder. Curcumin is a highly lipophilic and coexisted with oils and resins; it is very difficult to separate it from oils. However, it is soluble in polar solvents like ethanol, methanol, acetone, and acetic acid and also soluble in $0.1 \mathrm{~N}$ $\mathrm{NaOH}$ solution. It has a melting point of $173^{\circ}$.

In the present investigation curcumin was complexed with cobalt to obtain $\mathrm{Co}$ (II)-complex by reacting it with $\mathrm{CoSO}_{4}$ (fig. 1). FTIR spectroscopy and DSC have been employed for the characterization of complex. The complex was dark brownish in colour and was thermally stable above $>250^{\circ}$, soluble in DMSO and DMF, readily miscible with lipids and insoluble in water and show high melting point.

The spectrum of Co(II)-complex was assigned as follows, A broad band at $3410 \mathrm{~cm}^{-1}$ attributed to vibrations of free hydroxyl group of phenol (Ar-OH). An intense band at $1630 \mathrm{~cm}^{-1}$ attributed to vibrations of the carbonyl bond $(\mathrm{C}=\mathrm{O})$ accompanied by a smaller shoulder at $1742 \mathrm{~cm}^{-1}$ due to keto-enol tautomerism of curcumin compound. Three bands at 1590, 1506, $1457 \mathrm{~cm}^{-1}$ attributed to vibrational mode of $\mathrm{C}-\mathrm{O}$ elongation of alcohol and phenol groups (fig. 2).

DSC thermogram showed that curcumin is thermally stable up to $100^{\circ}$. Above this temperature an endothermic peak at $102^{\circ}$ was observed, which is related to the dehydroxylation of - $\mathrm{OH}$ groups by elimination of two water molecules. After $360^{\circ}$ curcumin started decomposing (fig. 3A). In contrast, Co(II)-complex was thermally stable up to $65^{\circ}$. Above this temperature two molecules of crystalline water was eliminated in one step at $86^{\circ}$ and $102^{\circ}$, respectively. The existence of an anhydrous complex $\left(\mathrm{Co}\left(\mathrm{H}_{2} \mathrm{O}\right)\right)$ could be evident from the plateau between 90 and $150^{\circ}$. Then, the sample shows melting endothermic peak at $283^{\circ}$, which can be related to the elimination of coordinated ligand. The intermediate was stable within the interval of $160-200^{\circ}$. After $366^{\circ}$ a chemical decomposition of curcumin occurs without formation of thermally stable intermediates (fig. 3B).

Good antibacterial activity was observed with both curcumin and its $\mathrm{Co}(\mathrm{II})$-complex (Table 1). Both the $\mathrm{Co}(\mathrm{II})$-complex and curcumin exhibited comparatively better activity against Gram-positive bacteria than Gram-negative bacteria. The MIC of Co(II)-complex

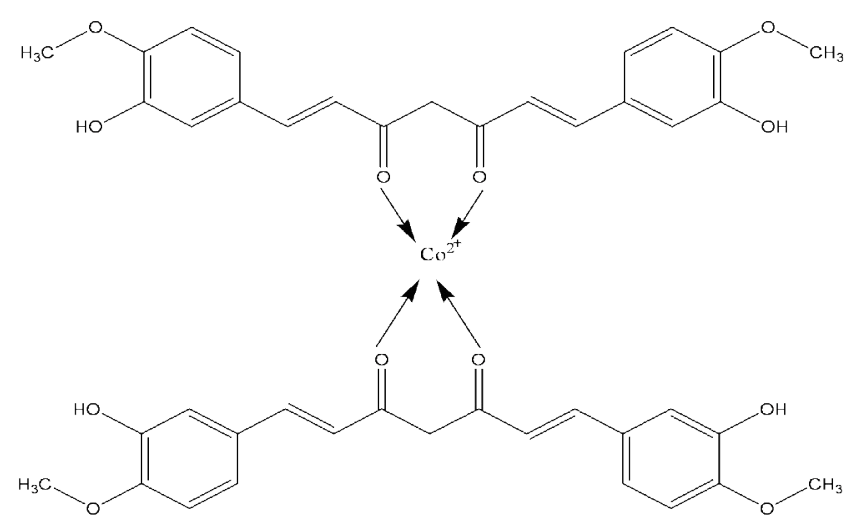

Fig. 1: Proposed structure of $\mathrm{Co}$ (II) complex of curcumin 


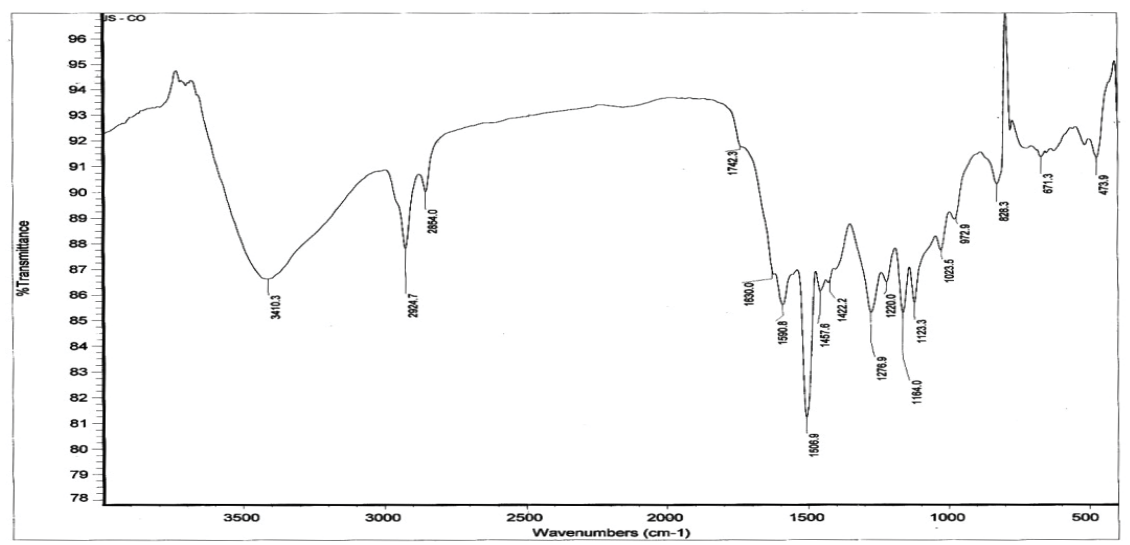

Fig. 2: IR spectrum of Co(II)-curcumin complex

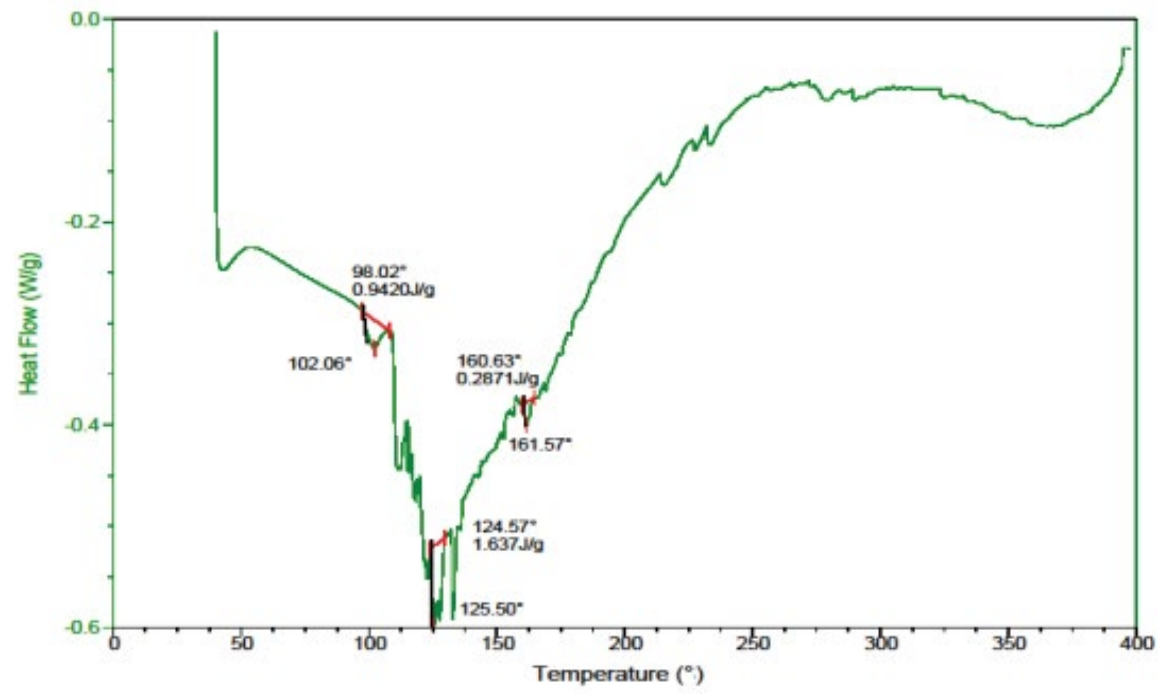

A.

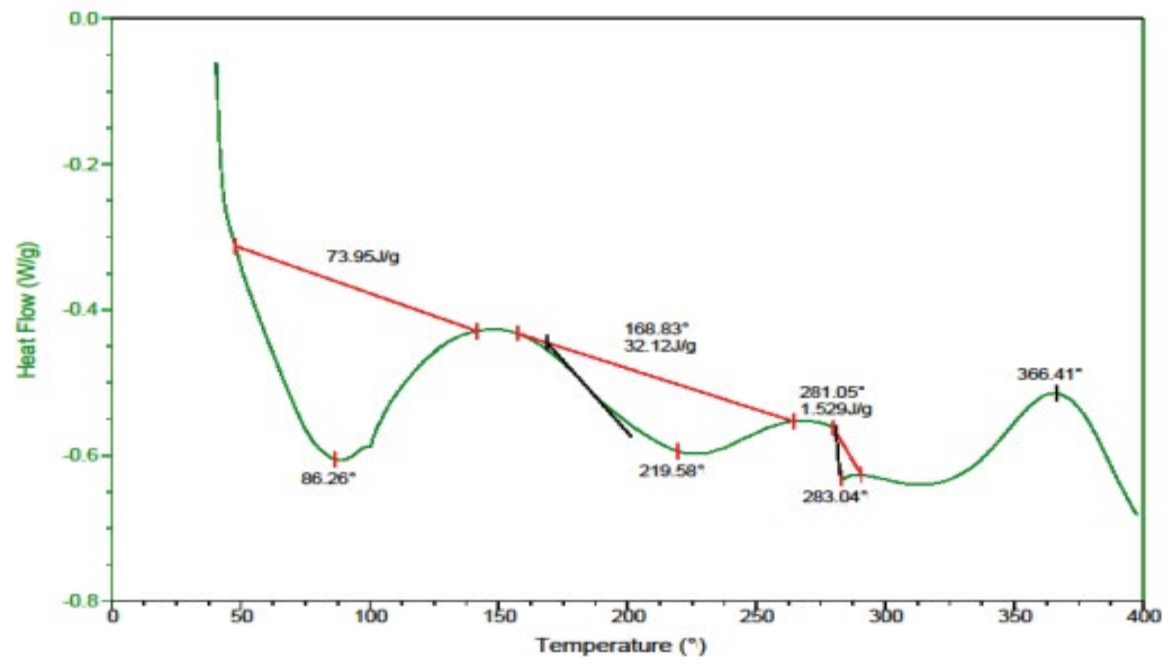

B.

Fig. 3: DSC thermogram of (A) curcumin, (B) Co(II)-curcumin

for Gram-positive bacteria was $3 \mathrm{mg} / \mathrm{ml}$ whereas that of curcumin was $4 \mathrm{mg} / \mathrm{ml}$. The MIC of Co(II)-complex for Gram-negative bacteria was $4 \mathrm{mg} / \mathrm{ml}$ whereas that of curcumin was $5 \mathrm{mg} / \mathrm{ml}$. The antibacterial activity of $\mathrm{Co}(\mathrm{II})$-complex $(6 \mathrm{mg} / \mathrm{ml})$ was similar to that of azithromycin at $15 \mu \mathrm{g} /$ disc (Table 2). Co(II)-complex exhibited comparatively better activity than curcumin. Similar results were reported by other workers. Other 
TABLE 1: ANTIBACTERIAL ACTIVITY OF CO(II)-CURCUMIN COMPLEX AGAINST BACTERIA

\begin{tabular}{|c|c|c|c|c|c|c|}
\hline \multirow{3}{*}{ Bacteria } & \multicolumn{6}{|c|}{ Zone of inhibition in $\mathrm{mm}$} \\
\hline & \multicolumn{6}{|c|}{ Co(II)-curcumin complex } \\
\hline & $1 \mathrm{mg} / \mathrm{ml}$ & $2 \mathrm{mg} / \mathrm{ml}$ & $3 \mathrm{mg} / \mathrm{ml}$ & $4 \mathrm{mg} / \mathrm{ml}$ & $5 \mathrm{mg} / \mathrm{ml}$ & $6 \mathrm{mg} / \mathrm{ml}$ \\
\hline Bacillus subtilis & 0 & 0 & $10.6 \pm 0.4$ & $14.8 \pm 0.3$ & $17.1 \pm 0.3$ & $21.1 \pm 0.3$ \\
\hline Escherichia coli & 0 & 0 & 0 & $8.8 \pm 0.3$ & $11.5 \pm 0.4$ & $13.8 \pm 0.2$ \\
\hline Klebsiella pneumoniae & 0 & 0 & 0 & $10.6 \pm 0.3$ & $12.4 \pm 0.2$ & $15.0 \pm 0.4$ \\
\hline Proteus vulgaris & 0 & 0 & 0 & $9.5 \pm 0.4$ & $13.1 \pm 0.3$ & $15.5 \pm 0.3$ \\
\hline Salmonella typhi & 0 & 0 & 0 & $10.1 \pm 0.3$ & $13.8 \pm 0.4$ & $16.5 \pm 0.3$ \\
\hline Shigella flexneri & 0 & 0 & 0 & $9.6 \pm 0.3$ & $13.8 \pm 0.3$ & $16.0 \pm 0.4$ \\
\hline Staphylococcus aureus & 0 & 0 & $9.3 \pm 0.3$ & $12.8 \pm 0.4$ & $15.8 \pm 0.3$ & $19.5 \pm 0.4$ \\
\hline \multicolumn{7}{|c|}{ Curcumin } \\
\hline Bacillus subtilis & 0 & 0 & 0 & $9.8 \pm 0.3$ & $12.6 \pm 0.4$ & $15.1 \pm 0.3$ \\
\hline Escherichia coli & 0 & 0 & 0 & 0 & $9.3 \pm 0.3$ & $11.1 \pm 0.3$ \\
\hline Klebsiella pneumoniae & 0 & 0 & 0 & 0 & $10.8 \pm 0.2$ & $12.8 \pm 0.3$ \\
\hline Proteus vulgaris & 0 & 0 & 0 & 0 & $11.3 \pm 0.3$ & $12.9 \pm 0.2$ \\
\hline Salmonella typhi & 0 & 0 & 0 & 0 & $10.0 \pm 0.2$ & $13.8 \pm 0.2$ \\
\hline Shigella flexneri & 0 & 0 & 0 & 0 & $11.1 \pm 0.3$ & $13.4 \pm 0.6$ \\
\hline Staphylococcus aureus & 0 & 0 & 0 & $10.2 \pm 0.3$ & $12.5 \pm 0.4$ & $14.4 \pm 0.2$ \\
\hline
\end{tabular}

The values are mean of six replicates \pm standard error

TABLE 2: COMPARISON OF ANTIBACTERIAL ACTIVITY OF CURCUMIN, CO(II)-CURCUMIN COMPLEX AND AZITHROMYCIN

\begin{tabular}{lccc}
\hline & \multicolumn{3}{c}{ Zone of inhibition (mm) } \\
\cline { 2 - 4 } Bacteria & Curcumin & Co(II)-complex & Azithromycin \\
\cline { 2 - 4 } & $\mathbf{6 ~ m g / m l}$ & $6 \mathrm{mg} / \mathrm{ml}$ & $\mathbf{( 1 5} \mathbf{~ m g / d i s c )}$ \\
\hline Bacillus subtilis & $15.1 \pm 0.3$ & $21.1 \pm 0.3$ & $20.4 \pm 0.3$ \\
Escherichia coli & $11.1 \pm 0.3$ & $13.8 \pm 0.2$ & $14.3 \pm 0.3$ \\
Klebsiella pneumoniae & $12.8 \pm 0.3$ & $15.0 \pm 0.4$ & $15.9 \pm 0.2$ \\
Proteus vulgaris & $12.9 \pm 0.2$ & $15.5 \pm 0.3$ & $14.8 \pm 0.2$ \\
Salmonella typhi & $13.8 \pm 0.2$ & $16.5 \pm 0.3$ & $17.2 \pm 0.3$ \\
Shigella flexneri & $13.4 \pm 0.6$ & $16.0 \pm 0.4$ & $16.5 \pm 0.4$ \\
Staphylococcus aureus & $14.4 \pm 0.2$ & $19.5 \pm 0.4$ & $18.8 \pm 0.2$ \\
\hline
\end{tabular}

The values are mean of six replicates \pm standard error

complexes such as indium curcumin and iron curcumin complexes were reported to exhibit better antibacterial activity than curcumin ${ }^{[17,31]}$. Synthetic modification of antibacterial agents was done in order to improve antibacterial activity or pharmacological properties ${ }^{[17]}$. Formation of metal complexes led to increased uptake by bacterial cells and thus enhanced the antibacterial activity ${ }^{[22]}$. Relatively more antimicrobial activity of $\mathrm{Co}$ (II)-complex than curcumin itself might be attributed to increased solubility, reduced metabolism and better cellular uptake, but required further investigations.

In conclusion, $\mathrm{Co}$ (II)-complex showed better antibacterial activity than curcumin and could be a suitable candidate for further in vivo investigations. This is the first report of antibacterial activity of Co(II)-complex against all the bacterial strains tested except $E$. coli. The fast growing research on curcumin and synthetic curcumin metal complexes confirmed the versatility and flexibility of curcumin for structural modifications. However, the actual role of different functionalities in curcumin in influencing its special physicochemical properties and pleiotropic effects of natural and synthetic curcuminoids is far from understood, which warranted further investigations.

\section{Acknowledgements:}

The authors are grateful to the University Grants Commission (SWRO), Bangalore, India, for financial assistance to carry out the work.

\section{Conflicts of interest:}

There is no conflict of interest. 


\section{REFERENCES}

1. Ashwini S, Girish K. Phytochemical screening and antibacterial activity of methanolic leaf extract of Coleus aromaticus Benth. Int J Res Pharm Sci 2014;5(4):270-4.

2. Ushimaru PI, Mariama TN, Luiz C, Di Luciano B, Ary FJ. Antibacterial activity of medicinal plant extract. Braz J Microbial 2007;38:717-9.

3. Pandey A, Gupta RK, Bhargava A, Agrawal B. Antibacterial activities of curcumin bioconjugates. Int $\mathrm{J}$ Pharmocol 2011;7:874-9.

4. Mohammadi K, Thompson KH, Patrick BO, Storr T, Martins C, Polishchuk E, et al. Synthesis and characterization of dual function vanadyl, gallium and indium curcumin complexes for medicinal applications. J Inorg Biochem 2005;99:2217-25.

5. Aggarwal BB, Sundaram C, Malani N, Ichikawa H. Curcumin: the Indian solid gold. Adv Exp Med Biol 2007;595:1-75.

6. De R, Kundu P, Swarnakar S, Ramamurthy T, Chowdhury A, Nair GB, et al. Antimicrobial activity of curcumin against Helicobacter pylori isolates from India and during infections in mice. Antimicrob Agents Chemother 2009;53(4):1592-7.

7. Mun SH, Joung DK, Kim YS, Kang OH, Kim SB, Seo YS, et al. Synergistic antibacterial effect of curcumin against methicillin-resistant Staphylococcus aureus. Phytomedicine 2013;20(8-9):714-8.

8. Tyagi P, Singh M, Kumari H, Kumari A, Mukhopadhyay K. Bactericidal activity of curcumin is associated with damaging of bacterial membrane. PLoS ONE 2015;10(3):e0121313.

9. Chen DY, Shien JH, Tiley L, Chiou SS, Wang SY, Chang $\mathrm{TJ}$, et al. Curcumin inhibits influenza virus infection and haemagglutination activity. Food Chem 2010;119(4):1346-51.

10. Sui Z, Salto R, Li J, Craik C, Ortiz de Montellano PR. Inhibition of the HIV-1 and HIV-2 proteases by curcumin and curcumin boron complexes. Bioorg Med Chem 1993;1(6):415-22.

11. Si X, Wang Y, Wong J, Zhang J, McManus BM, Luo H. Dysregulation of the ubiquitin-proteasome system by curcumin suppresses coxsackievirus B3 replication. J Virol 2007;81(7):3142-50.

12. Neelofar K, Shreaz S, Rimple B, Muralidhar S, Nikhat M, Khan LA. Curcumin as a promising anticandidal of clinical interest. Can J Microbiol 2011;57(3):204-10.

13. Chowdhury $\mathrm{H}$, Banerjee $\mathrm{T}$, Walia $\mathrm{S}$. In vitro screening of Curcuma longa $\mathrm{L}$ and its derivatives as antifungal agents against Helminthosporrum oryzae and Fusarium solani. Pest Res J 2008;20(1):6-9.

14. Martins CV, da Silva DL, Neres AT, Magalhães TF, Watanabe GA, Modolo LV, et al. Curcumin as a promising antifungal of clinical interest. J Antimicrob Chemother 2009;63(2):337-9.

15. Anand $\mathrm{P}$, Thomas SG, Kunnumakkara AB, Sundarama C, Harikumar KB, Sung B, et al. Biological activities of curcumin and its analogues (congeners) made by man and mother nature. Biochem Pharmacol 2008;76:1590-611.

16. Joseph J, Janaki GB, Nagashri K, Joseyphus RS, Dhanaraj CJ. Highly conjugated curcumin analog based copper complexes towards tuberculosis: synthesis, characterization and antimycobacterial activity. BMC Infect Dis 2012;12 (Suppl 1):P51.

17. Tajbakhsh S, Mohammadi K, Deilami I, Zandi K, Fouladvand $\mathrm{M}$, Ramedani $\mathrm{E}$, et al. Antibacterial activity of indium curcumin and indium diacetylcurcumin. Afr J Biotechnol 2008;7:3832-5.

18. Chattopadhyay I, Biswas K, Bandyopadhyay U, Banerjee RK. Turmeric and curcumin: biological actions and medicinal applications. Curr Sci 2004;87:44-53.

19. Kanhathaisong S, Rattanaphani S, Rattanaphani V, Manyum T. A spectroscopic investigation of the complex of turmeric dye with copper(II) in aqueous solution. Suranaree J Sci Technol 2011;18:159-65.

20. Rodrigues MA, Nunes Fernandes J, Ruggiero R, Guerra W. Palladium complex containing curcumin as ligand: Thermal and spectral characterization. Am J Chem 2012;2:157-9.

21. Zebib B, Mouloungui Z, Noirot V. Stabilization of curcumin by complexation with divalent cations in glycerol/water system. Bioinorg Chem Appl 2010;2010:292760.

22. David S, Barros V, Cruz C, Delgado R. In vitro effect of free and complexed indium(III) against Mycobacterium tuberculosis. FEMS Microbiol Lett 2005;251:119-24.

23. Hatamie S, Nouri M, Karandikar SK, Kulkarni A, Dhole SD, Phase DM. Complexes of cobalt nanoparticles and polyfunctional curcumin as antimicrobial agents. Mater Sci Eng C 2012;32:92-7.

24. Chang EL, Simmers C, Knight DA. Cobalt complexes as antiviral and antibacterial agents. Pharmaceuticals 2010;3:1711-28.

25. Stănilă A, Braicu C, Stănilă S, Pop RM. Antibacterial activity of copper and cobalt amino acids complexes. Not Bot Horti Agrobo 2011;39(2):124-9.

26. Saha S, Dhanasekaran D, Chandraleka S, Panneerselvam A. Synthesis, characterization and antimicrobial activity of cobalt metal complex against multi drug resistant bacterial and fungal pathogens. Adv Biol Res 2010;4(4):224-9.

27. Khurshid S, Shah S, Qurat-ul-Ain, Arshia, Maqsood ZT, Tauseef S, Khan MK. Synthesis, characterization and antimicrobial activity of thiamine complexes. Lett Drug Des Discov 2018;15:1276-87.

28. Martak F, Cahyani NWD, Nugraheni ZV, Utomo WP. Properties and toxicity of cobalt(II) complex with 2,4,5-triphenyl-1Himidazole ligand. Indones J Chem 2016;16(3):260-7.

29. Sastry BS. Curcumin content of turmeric. Res Ind 1970;15(4):258-60.

30. Savita AM, Dawra C, Bhat K. An in vitro evaluation of antibacterial activity of curcumin against Aggregatibacter actinomycetemcomitans. World J Dent 2015;6(1):16-9.

31. Bagchi A, Mukherjee P, Bhowmick S, Raha A. Synthesis, characterization and antibacterial activity of a novel curcumin metal complex. Int J Drug Dev Res 2015;7:11-4. 